\title{
Students' Digital Photography Behaviors during a Multiday Environmental Science Field Trip and Their Recollections of Photographed Science Content
}

\author{
Victor R. Lee \\ Department of Instructional Technology and Learning Sciences, Utah State University, 2830 Old Main Hill, \\ Logan, UT 84321, USA \\ Correspondence should be addressed to Victor R. Lee; victor.lee@usu.edu \\ Received 15 January 2014; Accepted 7 May 2014; Published 2 June 2014 \\ Academic Editor: Gwo-Jen Hwang \\ Copyright (C) 2014 Victor R. Lee. This is an open access article distributed under the Creative Commons Attribution License, which \\ permits unrestricted use, distribution, and reproduction in any medium, provided the original work is properly cited.

\begin{abstract}
Taking photographs to document the experiences of an educational field trip is becoming a common activity for teachers and students alike. Considering the regular creation of photographic artifacts, our goal in this paper is to explore students' picture taking behavior and their recollections of science content associated with their photographs. In this study, we partnered with a class of fifth-grade students in the United States and provided each student with a digital camera to document their experiences during an environmental science field trip at a national park. We report the frequency of photography behaviors according to which activities were most often documented by the students and specifically that students tended to document more of their experiences when they were in outdoor, natural spaces rather than inside of visitor centers or museums. Also, through an analysis of students' comments about the science content captured in their photographs we observe that students' comments about photographs of the outdoors tended to show greater depth and complexity than those that were taken in indoor, museum-like spaces.
\end{abstract}

\section{Introduction}

Field trips are an important vehicle through which classrooms of students and teachers are able to engage with and learn about the natural world through integrated processes of immersion and direct observation $[1,2]$. They are noteworthy for educators because they may lead to improved content understanding of and attitudes relevant to the natural environment $[3,4]$ and also because they can produce longterm memories of specific learning experiences that have the potential of enduring for several years [5-7]. In the literature related to recall of field experiences, these memories are often identified and treated as strictly mental phenomena. That is, memory is often conceptualized, sometimes tacitly, as a recapitulation of information stored in a mental encoding. However, it is also worth recognizing that memory, as well as many other cognitive processes, can alternately be seen as not only a mental phenomenon but also a material one [8]. Various artifacts or creations from an experience can serve a central role in the act of "remembering," and it is through these creations that we piece together recollections of lived experiences.

In this study, we take the idea of photographs as a form of externalized memory seriously and consider what is captured during an environmental science field trip experience using this medium. The capture of photographic records on field trips has been noted as an activity largely undertaken by adults, such as a classroom teacher who is obtaining documentation of the experience [9]. However, with the proliferation and decreasing prices of digital cameras, it is now common to see children on field trips obtaining their own photograph images. Indeed, photography capabilities are so abundant and pervasive in daily life that scholars who examine youth culture and technology have been working to raise awareness of the research possibilities associated with youth's photographs (e.g., [10]). For this study, we focused on photographs taken by a class during an environmental science field trip experience at a national park and reported a frequency analysis of students' pictures over time and an analysis of students' reflections of science content from 
their photographs. In addition to sharing these findings, this paper is also intended to advance the education research community's knowledge of what students take away from field trip experiences and demonstrate the potential of using a set of everyday artifacts created by students as a source of data.

In the sections that follow, we will describe our theoretical perspective and then briefly describe a small but growing base of literature in which photographs are used in educational research. Then, we describe the design of our research study, including details about the field trip experience that we examined. Following this, we present two analyses of our data: a frequency analysis of activities that were most often photographed and a comparison of students' commentaries about science content encountered across two heavily promoted types of field trip activities: nature walks and museum visits. We conclude with some consideration of how photographs may have value for both learners and researchers.

\section{Theoretical Perspectives}

In pursuing this study, we maintain a distributed cognitive stance in which we think of externalized artifacts and representations, such as photographs, to be key in cognitive processes such as memory and recall [8]. Additionally, we are deliberately centralizing the experiences and perspectives of the learners within a learning setting. Ever since early research done by Piaget (e.g., [11]), there has been a recognition that children have already developed a wealth of views and ideas about the world around them by the time they are formally enrolled in school [12]. Often, this has been approached as a question of the nature and content of students' naïve conceptualizations. For instance, there is a tremendous body of research that has examined students' ideas and mental models of the natural world (e.g., [13]). However, we believe that part of the abilities and tendencies that come along with informally developed understandings of the world includes inclinations to exhibit selective attention to different features of their environments.

This form of selective attention has been receiving more attention in education research, with some characterizing the behavior as a form of "noticing" [14-16]. In the case of experts within a community of practice, it can also be described as a form of professional vision [17]. Stated simply, groups of people who are engaged in recurring types of work or activity develop sensitivities to aspects of their environments suited to the needs of their activity and the knowledge that they have developed or may be in need of developing. Not only do these sensitivities direct the immediate acts of perception (i.e., shifting the direction of gaze or duration of fixation) but also they come associated with a body of cued knowledge. For instance, an archaeologist may notice textures or colors in soil and be able to immediately make some inferences about the kinds of structures that had previously been placed there or a teacher may, upon hearing a question about a mathematical symbol, be able to make some inferences about the state of that student's conceptual understanding. For students, we expect that there are comparable tendencies, but they are tuned to ways of thinking about and engaging with designed learning activities. Given that expectation, it follows that we as researchers should be attentive to objects and scenes that children notice and to the ideas and knowledge that are cued in response.

The other theoretical concern we maintain relates to what has been termed as "place-based education" (e.g., [18, 19]). The central assumption of place-based education is that a driving force in the design of an educational experience should be the utilization of the immediate locations inhabited by a group of learners. For example, a school in an urban locale may begin to investigate their use of space and their mobility patterns within their neighborhoods, examine the governmental and development policies that have led to the current state, and make recommendations to municipal leaders for a new set of urban development plans given what they have learned [20]. Place-based education has seen substantial interest in environmental and outdoor education. However, one key distinction for environmental and outdoor education in comparison to the neighborhood mobility example is that outdoor environmental education emphasizes natural environments rather than designed ones [21]. However, at their roots, all these pedagogical perspectives trace some of their roots to Dewey [22], particularly with regard to his discussions about the importance of experience in education and forms of learner-driven inquiry as part of experience.

Place-based approaches contend that there is a wealth of learning potential that can be immediately relevant to students because they will leverage access and informal knowledge about the immediate setting around them. For several contingents of outdoor and environmental educators, this view of place-as-resource has particularly struck a chord because the settings are intact, natural ecosystems. Thus, it follows that such settings are ideal for learning about wildlife, plant ecology, geological processes, and the dynamics of ecosystems. Indeed, some research has confirmed that learning gains in these areas do occur $[4,23]$.

What is still uncertain, however, is how knowledge encountered during short-term exposure to place-based learning is developed and retained. In an extended outdoor camp experience, we can expect students to be involved in place-based learning for a period of weeks or months. However, the typical school field trip to a particular natural location lasts for one day or, at most, for a couple of days and nights. We know that science field trip experiences and the novelty that they afford can produce enduring memories (e.g., [5]), but the abrupt exposure to new settings and experiences can also produce a novelty effect where students are so distracted by new things they are seeing that they do not demonstrate improvement in the content learning targeted by the trip $[23,24]$. Thus, we believe that some empirical consideration of what children notice when they are introduced to and immersed in a natural environment that is presented through a place-based pedagogy is merited.

\section{Photographs as an Object for Research}

A distinguishing feature of the current study is our focus on photographs. While there has been some precedent 
for considering photographs in science and environmental educational research, the research emphasis has largely been on photographic images that are produced and presented to students through instructional materials (e.g., [25-27]). These treatments consider photographs as a tool of instruction, and they are largely concerned with how photographs are used by educators to represent a field of study. In contrast, we are approaching photographs as a form of "participantcollected data" [28]. We want photographs to be a medium through which we can come to understand both the activity that students completed and their subjective experiences and recall as mediated by the images they had obtained $[29,30]$. This approach differs subtly from other manners of using photographs in research on learning experiences, such as when photographs obtained through a third party are used as tools for supporting "stimulated recall" [31, 32]. In stimulated recall research, photographs are given as reference points for things that students might have seen, but, because they are obtained by a researcher or from someone with outsider status, they impose an external viewpoint on how a particular activity should be remembered or understood. Thus, the perspective of the student is, at least to some degree, marginalized.

In contrast, by letting the student be the documenter of experience, a greater priority is placed on the students' lived experiences. This has proven fruitful, particularly in qualitative research of learning environments. For example, Reeve and Bell [33] conducted a photo-elicitation study in which 9-11-year-old students took photographs from their everyday experiences to illustrate how they understood the science associated with the terms "healthy" and "unhealthy." In contrast to the extant science education literature on students' understandings of health, which tended to focus on researcher-defined notions of illness, the authors found that students had a far more multifaceted view of what health looked like in their homes. Students' ideas about health spanned across ideas related to nutrition, cleanliness, and pleasurable experiences and thus were tied to meanings that researchers often fail to consider. Smith and colleagues [34, 35] found that college-aged individuals who were diagnosed with type 1 diabetes and situated in a support group of others who were learning to cope with diabetes were able to document and discuss a variety of challenges that they experienced with respect to maintaining a healthy lifestyle, some of which are not always anticipated by researchers or physicians. Orellana [36] found students' photographs to be a powerful method to aid her in understanding qualitatively the spaces inhabited by immigrant students in an urban area and the role of personal and social relationships that defined their community landscapes.

In addition to helping researchers understand the experiences and perspectives of students, students' use of a camera within a learning environment can also positively affect their engagement and participation within that learning space. For example, Ching, Wang, Shih, and Kedem [37] documented how students in a K-1 classroom shifted and negotiated their roles as students in the classroom and through their behaviors in the class and demonstrated increased empowerment when a digital camera was provided for them to use. Tatar and
Robinson [38] found that when students in a high school biology course were provided with digital cameras to use for documenting their lab activities, students showed greater science process knowledge and interest in the activity than those of a control group, likely because of their role as designated activity documentarians.

The literature on photography research in education is modest, perhaps with its greatest presence in the field of visual sociology [30]. When it has been used in most areas of education research, the emphases are placed on students' experiences in their homes and neighborhoods. This paper aims to expand that focus to learning experiences beyond the school and home, which have been documented in the above studies. Our contribution to the photograph-based education research literature will be some initial details about photography behaviors during a field trip, and, in particular, one to a US national park.

\section{Research Context}

In the United States, the national park system was established in the early 20th century to preserve exceptional regions of natural land formations and geological processes for both research and recreation. For this study, we partnered with a team-taught fifth-grade class from a public elementary school located in Utah that was scheduled to participate in an annual field trip to Grand Teton National Park (GTNP), a US national park in the western United States known for mountainous ranges formed by glaciers and a woodland ecosystem populated by animals such as bears, moose, elk, beavers, and bison as well as plant-life such as lodge-pole pines, Douglas firs, aspen, sagebrush, and huckleberry plants. This was a trip that fifth-grade students in the school had taken for over 10 years. It was regularly hosted at Teton Science Schools (TSS) (http://www.tetonscience.org/), an independently run, nonprofit outdoor education program that emphasized naturalistic scientific inquiry and placebased pedagogy. TSS provides Teton-based educational programming for a number of visiting student and adult groups throughout the year and provides pedagogical training for outdoor educators and K-12 teachers.

The field trip took place within the first three months of the school year and lasted for four days and three nights. The content goals for the field trip related to understanding specific ecosystems, including biotic and abiotic factors influencing changes in ecosystem populations, and identifying various plant and animal species using a range of indicators and markers such as tracks, appearance, and scat composition. Additionally, there was a goal of helping students to recognize the influence of glacial movement and other forces involved in creating land formations. Finally, another learning goal was to ensure that all the students could describe and engage in a full cycle of guided inquiry complete with the development of a researchable question, collection of data, analysis of data, and publicly communicating results.

In preparation for the trip, the fifth-grade teachers sequenced their classroom science curriculum so that they covered science content related to weathering, erosion, and local wildlife immediately prior to the trip. The teachers also 
regularly highlighted two types of unique experiences that students would have. These included (1) hikes to beautiful natural scenery where the students would learn about the environment and also (2) visits to museum spaces where students could view collections of artifacts and specimens obtained by naturalist scientists who had conducted research in the Grand Teton Area. They travelled by charter bus from Utah to Grand Teton National Park and made necessary stops on days 1 and 4 of the trip.

At TSS, trained outdoor education guides led groups of less than 10 students on excursions each day. These included an orientation hike on the first day to a nearby river (Table 1 , item $1 G$ ), an extended hike on the second day within the Bridger-Teton National Forest intermixed with discussion of plant-life and ecosystems $(2 \mathrm{C}-2 \mathrm{~F})$, and a third hike that led to a nature investigation within the local ecosystem related to animal or plant-life (3C-3G). The guides also served as docents in other learning spaces that students visited during the trip. For example, students had blocks of time in a large common room that had a number of "exploration" stations with different artifacts (such as pelts, plant materials, rocks, etc.) and informational or investigative resources (e.g., rulers, guide books, and magnifying glasses) (Table 1: items 1), 2B, $2 \mathrm{~J}, 3 \mathrm{~B}$, and $3 \mathrm{~K})$ to facilitate identification of species. Trained guides would engage with small groups of students at these stations each day.

During the trip, students also participated in other indoor educational activities that included visiting an onsite museum $(2 \mathrm{~K})$ or engaging in group communication exercises $(1 \mathrm{~K})$. Some free-play breaks of roughly an hour were scheduled for each day $(1 \mathrm{H}, 2 \mathrm{H}$, and $3 \mathrm{I})$ during which students could play with outdoor sports equipment or board games in the common room. On the final day, the class stopped at a famous landslide site (4D), made an unplanned visit to an intact beaver lodge (4E-F) to look at a real habitat constructed and used recently by beavers, and made a stop at the GTNP visitor's center to purchase souvenirs $(4 \mathrm{H})$. A full list of the field trip activities during which students had possession of cameras to document their experiences is provided in Table 1.

\section{Data Sources}

We provided each student in the class $(N=27)$ with a point and shoot digital camera (either a Kodak EasyShare C182 or a Nikon CoolPix 3100) and a minimum of a 4-gigabyte memory card. The students' parents had all agreed to let their children use project cameras only (rather than any personal cameras). All participating students and their parents had provided consent to be in this study, to be photographed, and to allow researchers to collect and retain copies of all student photographs for research. The TSS staff was notified of the research and during the trip the TSS staff explicitly invited students to take pictures of anything they wished during the various planned activities. This even included snapping pictures while adults were talking or presenting lessons. The full corpus of photographs students had taken thus serves as one set of data for this work.
TABLE 1: Sequence of activities when students had possession of digital cameras.

\begin{tabular}{|c|c|c|}
\hline Day & Activity & $\begin{array}{l}\text { Approximate } \\
\text { duration }\end{array}$ \\
\hline \multirow{11}{*}{1} & (A) Bus ride to Soda Springs, Idaho & $1.5 \mathrm{~h}$ \\
\hline & (B) Soda Springs Geyser & $1 \mathrm{~h}$ \\
\hline & (C) Bus ride to Jackson, Wyoming & $2 \mathrm{~h}$ \\
\hline & (D) Lunch in Jackson & $1 \mathrm{~h}$ \\
\hline & (E) Bus ride to Teton Science School (TSS) & $1 \mathrm{~h}$ \\
\hline & (F) Orientation meeting with TSS staff & $1 \mathrm{~h}$ \\
\hline & (G) First hike to river (led by TSS staff) & $1 \mathrm{~h}$ \\
\hline & (H) Free-play afternoon break & $1 \mathrm{~h}$ \\
\hline & (I) Dinner & $1 \mathrm{~h}$ \\
\hline & (J) Evening exploration station activities & $0.5 \mathrm{~h}$ \\
\hline & (K) TSS staff-led communication activities & $1 \mathrm{~h}$ \\
\hline \multirow{11}{*}{2} & (A) Breakfast & $1 \mathrm{~h}$ \\
\hline & (B) Morning exploration station activities & $0.5 \mathrm{~h}$ \\
\hline & (C) Van ride to major Bridger-Teton trailhead & $0.5 \mathrm{~h}$ \\
\hline & (D) Hike to mountain lake & $2.5 \mathrm{~h}$ \\
\hline & (E) Staff-led geology discussion at lake & $1 \mathrm{~h}$ \\
\hline & (F) Return hike to trailhead & $2.5 \mathrm{~h}$ \\
\hline & (G) Van ride back to TSS & $0.5 \mathrm{~h}$ \\
\hline & (H) Free-play afternoon break & $2 \mathrm{~h}$ \\
\hline & (I) Dinner & $1 \mathrm{~h}$ \\
\hline & (J) Evening exploration station activities & $0.5 \mathrm{~h}$ \\
\hline & (K) Visit to TSS museum & $1.5 \mathrm{~h}$ \\
\hline \multirow{13}{*}{3} & (A) Breakfast & $1 \mathrm{~h}$ \\
\hline & (B) Morning exploration station activities & $0.5 \mathrm{~h}$ \\
\hline & $\begin{array}{l}\text { (C) Staff-led meetings to discuss guided } \\
\text { nature investigations }\end{array}$ & $1 \mathrm{~h}$ \\
\hline & (D) Transit to investigation site trailheads & $0.5 \mathrm{~h}$ \\
\hline & (E) Guided nature investigations & $3 \mathrm{~h}$ \\
\hline & (F) Return transit to TSS & $0.5 \mathrm{~h}$ \\
\hline & (G) Investigation presentation preparation & $2 \mathrm{~h}$ \\
\hline & (H) Student cleaning of TSS facilities & $0.5 \mathrm{~h}$ \\
\hline & (I) Free-play afternoon break & $1 \mathrm{~h}$ \\
\hline & (J) Dinner & $1 \mathrm{~h}$ \\
\hline & (K) Evening exploration station activities & $0.5 \mathrm{~h}$ \\
\hline & (L) Investigation presentations & $1.5 \mathrm{~h}$ \\
\hline & (M) Cabins & $\mathrm{n} / \mathrm{a}$ \\
\hline \multirow{9}{*}{4} & (A) Breakfast & $1 \mathrm{~h}$ \\
\hline & $\begin{array}{l}\text { (B) Departure preparation (packing, loading } \\
\text { buses) }\end{array}$ & $1 \mathrm{~h}$ \\
\hline & (C) Bus ride to Gros Ventre landslide & $0.5 \mathrm{~h}$ \\
\hline & (D) Teacher-led hike at Gros Ventre landslide & $0.75 \mathrm{~h}$ \\
\hline & (E) Bus ride to beaver lodge & 0.5 \\
\hline & (F) Student examination of beaver lodge & $1 \mathrm{~h}$ \\
\hline & (G) Bus ride to Visitor Center & 0.25 \\
\hline & (H) Visitor Center Gift Shop & $1 \mathrm{~h}$ \\
\hline & $\begin{array}{l}\text { (I) Bus ride away to Jackson, Wyoming, for } \\
\text { lunch }\end{array}$ & $\mathrm{n} / \mathrm{a}$ \\
\hline
\end{tabular}


We also collected interviews with several students. One week after the trip, the author and a trained assistant individually met with students and provided them with a laptop and a slideshow of all of their pictures. The students were given full navigation control of the slideshow so that they could skip any pictures that they did not wish to discuss (if, for instance, the content might have been embarrassing to them). During the interview, students were asked to talk about the pictures they had taken and why they took them. The interviewer would interrupt with clarification questions and would periodically remind students of the commentary they were being asked to provide should they cease to offer it after viewing multiple pictures. All these interviews lasted roughly an hour and were each video-recorded and transcribed. In total, we ended with interviews from 18 randomly selected students.

Finally, we recorded observational notes from the field trip. The first author obtained permission to join the field trip as an additional, nonparent chaperone. Each day, he accompanied a different one of the three field groups when there were activities that the field groups completed separately. Throughout his participation, the first author took regular field notes, following guidelines recommended by Emerson et al. [39]. His involvement was limited in that he did not facilitate or lead any of the days' educational activities. He did, however, spend time talking with students, eating with them, and participating in the occasional outdoor game along with other chaperones in order to build rapport. He also provided technical support for any cameras that malfunctioned or needed new batteries.

\section{Analyzing Photography Behaviors: Frequencies of Documentation}

Field notes were used primarily to index the different days' events into discrete activities. These activities ranged roughly from half an hour to three hours in duration and included activities such as bus rides, guided hikes, visits to designated locations, meals, and free exploration time. Photographs were organized into a database and coded based on which student took the photograph, the associated event, if it was a unique image (as opposed to a duplicate image), and general information about the contents of the photograph (e.g., mountain ranges, a body of water, animal scat, a skeleton, a tree, etc.). We identified 44 activities to be included in our analysis.

In total, we had obtained 4,178 photographs from 26 students (one student lost his camera on day 3 ). This translated to an average of 161 photographs taken per student $(\mathrm{SD}=122)$. However, included in these numbers were duplicate photographs in which the same student took several pictures of the same object or scene. There were a total of 1,243 duplicate photographs, which translated to roughly 50 duplicates per student $(\mathrm{SD}=62)$. This means that on average roughly one-third of all the images that students retained were duplicates-even after undesired ones were deleted. Based on a visual analysis of a graph of when duplicates were taken, we ascertained that duplicates appeared to be evenly distributed across events. That is, there was little evidence supporting the claim that certain events invited more duplicate pictures. More often than not, students wanted to make sure they had clear images and had more than enough space on their cameras to take extra pictures. Regardless, we excluded duplicates from the subsequent numerical analyses to reduce inflation of any calculations. The resultant breakdown of photographs taken and students taking photographs for each activity is shown in Figure 1.

We then identified the top five most heavily photographed events. There were the day 2 hike (Table 1, 2D) (429 photographs, 24 students), the day 3 hiking and investigations (Table 1, 3E) (352 photographs, 22 students), the day 1 stop at the Soda Springs Geyser (Table 1, 1B) (306 photographs, 24 students), the day 1 hike (Table 1, 1G) (212 photographs, 24 students), and the day 2 van rides from the trailhead back to TSS (Table 1, 2G) (239 photos, 21 students). As the hikes were repeatedly emphasized by the classroom teachers as one of the major activities students would experience on the field trip, we found the relative number of photographs during their hikes to be close to what we expected. The geyser was the first stop after students received their cameras for the trip, and thus the students likely took many photographs because they were eager to start using the cameras.

The number of photographs from the van ride back to TSS (Table 1, 2G) was more puzzling. As it turned out, one of the three guide groups had opted to stop by the GTNP visitor's center that housed a small museum and exhibits about the geography and ecosystems of GTNP. Of the 239 pictures by all students in the class taken during that time block, 141 (58\%) were pictures from within the museum area of the visitor's center and were taken by a third of the class. Museum spaces were one of the other experiences emphasized by the teachers prior to the trip, and thus the volume of pictures taken by a subset that visited the museum area of the visitor's center is consistent with what we would expect. We discovered that the intention was for more students to partake in the museum experience at the visitor's center, but the timing and pace of each subgroup with respect to the day's schedule made it so only one of the three subgroups was able to make that visit that day. However, all students participated in a nighttime visit to the museum housed at the TSS campus, and the combination of photographs from the visitor's center and the campus museum together still allowed us to perform an additional analysis on pictures taken during hikes and in museum spaces, described below.

\section{Analyzing Student Reflections about Their Photographs}

We had expected hikes and museum spaces to yield more photographs than other activities (such as meals or games). Museum spaces were not as heavily photographed as not all students were able to visit the GTNP Visitor Center Museum. And, although students had cameras with them, the author observed that the students were far less likely to take pictures in the TSS museum. During the transcription phase of our study, we noticed also in students' commentaries about their photographs that some students had more to say about images taken during a hike than they did for comparable 


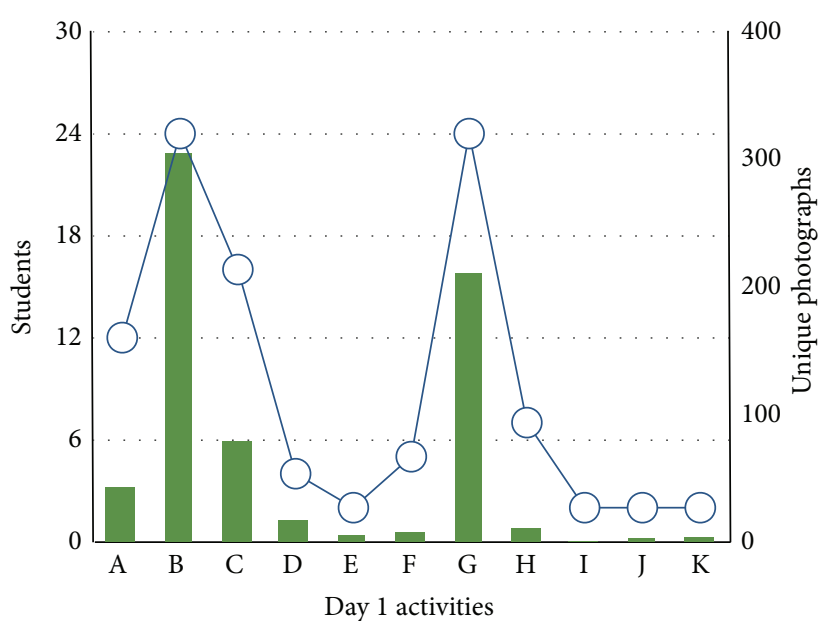

(a)

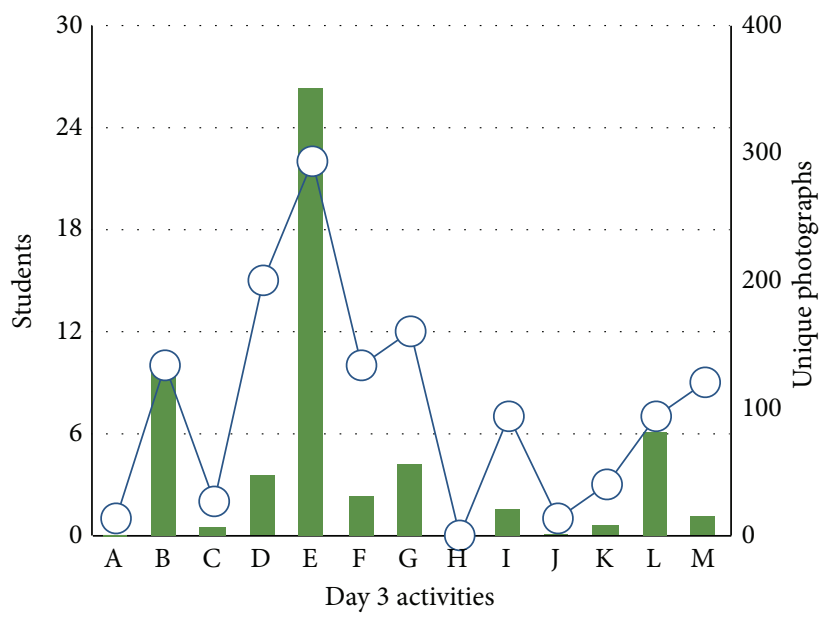

(c)

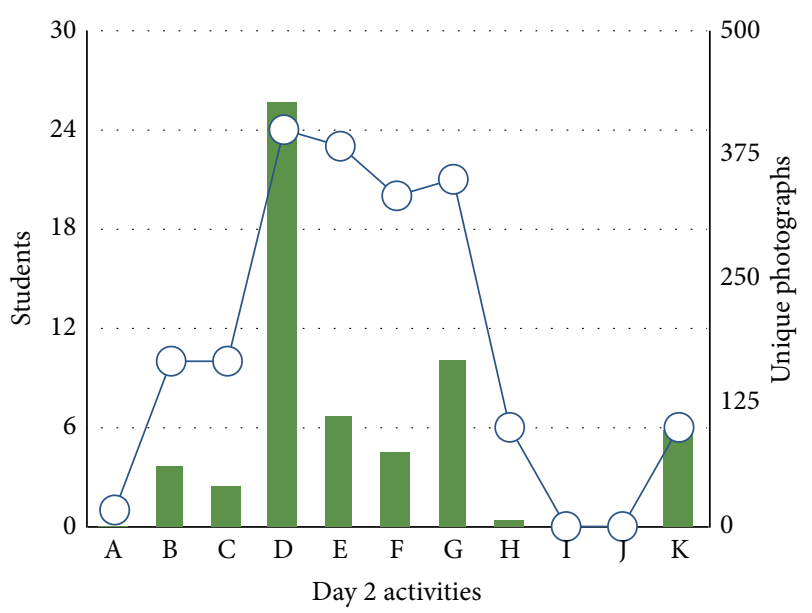

(b)

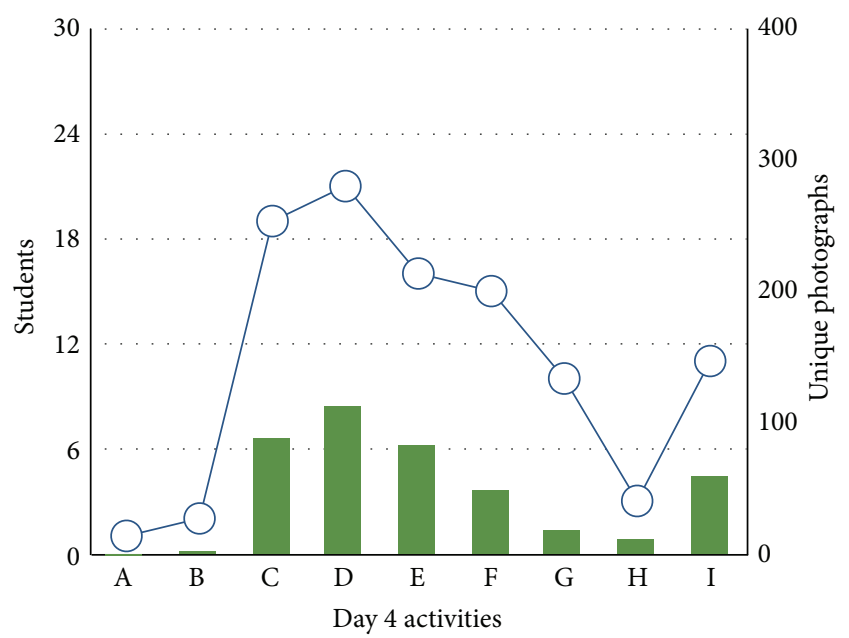

(d)

FIGURE 1: Number of students who had taken photographs of an event (line graph) and number of unique photographs taken during an event (bar) for each day of the field trip. Please note that alphabetic coding of activities is derived from Table 1.

objects when encountered in a museum. Figure 2 illustrates this with two instances of animal skeleton photographs and accompanying reflection from students.

In order to determine if this reflected a real difference, we developed a coding scheme for students' reflections about their pictures obtained during hikes on days 1, 2, and 3 of the trip and compared it with comments made about photographs taken at the two museum spaces. Our coding scheme included four categories for students' comments about their pictures.

(i) Documentation. When a student's commentary about a photograph indicated that they took a particular picture strictly for archival reasons, such as documenting a unique sight, without much additional details, this code was applied.

(ii) Observations. When comments about the pictures had more specific descriptive details about some feature, attribute, or approximated measurement, we coded the commentary as involving an observation.
For example, a student comment about sizes of antlers in a photograph relative to their bodies (e.g., "they was as long as my arms!") would be considered as an observation since it resembled an empirical description.

(iii) Inferences were coded when students became more speculative or when they suggested a chain of events that were associated with the picture. For instance, some students who took pictures of large boulders stated that they did so because they believed that a glacier movement was involved in the boulder's placement, and they had inferred that since glaciers could move large rocks and were involved in forming the local landscape.

(iv) Wonderment was coded when students articulated a question that motivated them to take the picture. As an example, upon seeing an animal skull, a student would describe how they wondered what different curvatures or holes in the skull were for. Wonderment 


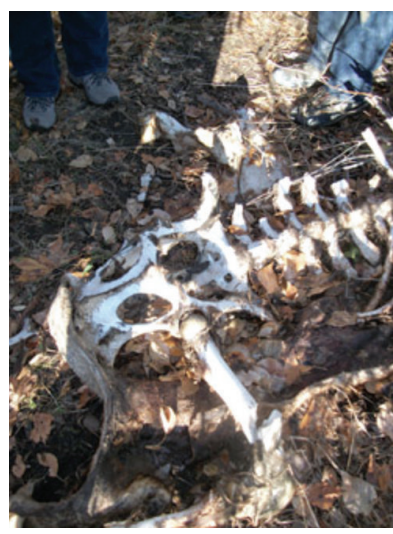

(a)

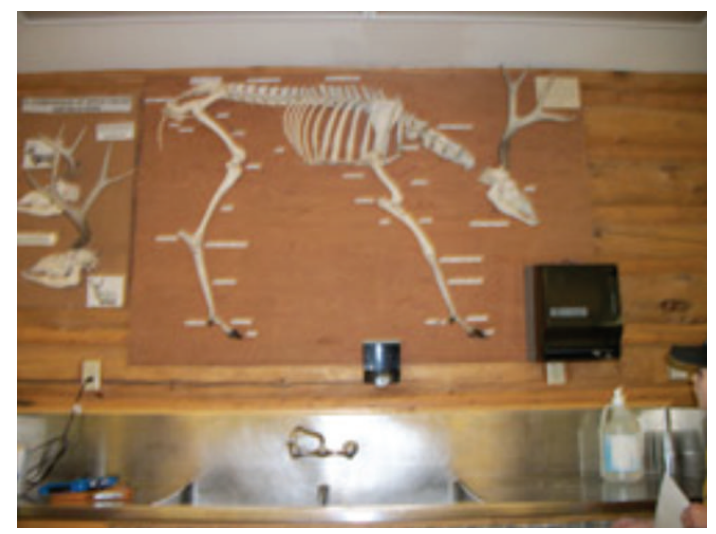

(b)

Figure 2: A comparison of animal skeleton photographs taken (a) during an outdoor activity and (b) within a museum space at the host facility. Students' reflections, as obtained in the interviews, are provided. (a) And this you can see, it is cracked right there, and you can see the fur, and you can see the hip bone, but there was two rib cages...this one was not entirely broken so we (my friends and I) are guessing that this one had stronger bones, and we are guessing it was a bison, and we are guessing this one is a moose or an elk, and we think a wolf went after these two. Student 13 And this is a picture of an animal, I think it is probably like a... I do not know...but it is bigger than me. Student 11.

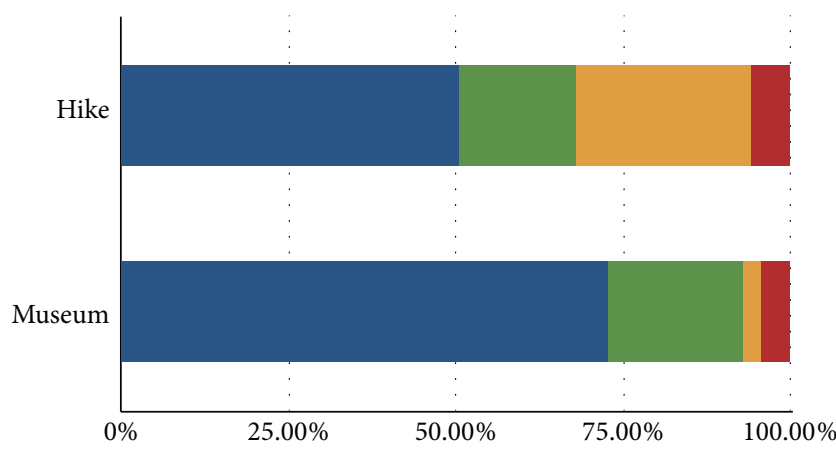

FIGURE 3: Blue indicates the percentage of students' comments about their photos that were coded as documentation. Green indicates the percentage of students' comments that were coded as observations. Yellow indicates the percentage of students' comments coded as inferences. Red indicates codings for wonderment.

questions were musings and wonderings that students had that could, in principle, be empirically investigated.

We developed these codes so that their sequencing could be seen as reflecting an increase in level of sophistication, especially when considered against recognized conceptual organizational schemes such as Bloom's taxonomy [40]. Only one code could be applied to each photo commentary, and if multiple codes applied, we assigned the "more sophisticated" code. After developing this coding scheme, the author and a trained research assistant independently coded the same subset (164 pictures with student comments) and these codes were compared for interrater reliability. We obtained $91 \%$ agreement $(\kappa=0.83)$. Given a desirable level of reliability, we proceeded to independently code the rest of the museum and hike commentaries. The distribution of these codes across the museum and hike sets is shown in Figure 3.
To compare the two distributions, we used a CochranMantel-Haenszel test. The Cochran-Mantel-Haenszel test is an exact test used primarily in biological and epidemiological research $[41,42]$ when working with categorical data that may have a hidden covariate. Stated in another way, in this pool of student photographs we have unequal numbers of repeated samples obtained across different students. Some students tended to take more pictures and others tended to take fewer, independent of duplicates of a given image. Given that, it is possible that any differences in coding of comments are attributable to tendencies of individual students who tended to provide differing levels of commentary. For example, students who took fewer unique pictures might have been more selective and had more thoughtful commentaries. The Cochran-Mantel-Haenszel test controls for these possible factors.

When we compared the commentaries (using SAS) from the hike experiences and from the museum experiences, there was indeed a significant difference in the distributions $(P<$ $0.0001)$. There appeared to be more documentation for the museum experiences $(72.8 \%$ documentation for museum, $50.1 \%$ for hikes) and more inferences during the hike experiences (26.1\% inference for hikes, $2.6 \%$ for museums). Wonderment and observations were roughly comparable between the two groups (5.9\% wonderment for hikes, $4.4 \%$ for museums; $17.4 \%$ observation for hikes, $20.2 \%$ for museums).

These results suggest that, in a field trip such as this, the field experiences encouraged more student inferences and less documentation. Recall that there was a guide present with the students who was directing their attention and was available to provide just-in-time interpretations of what was being encountered. Students also had time to freely explore and make their own discoveries. Based on the field notes and the firsthand observations made by the author, these activities both still took place in the museums. In fact, several photographs from students included images of their field leader explaining different artifacts in the museum 


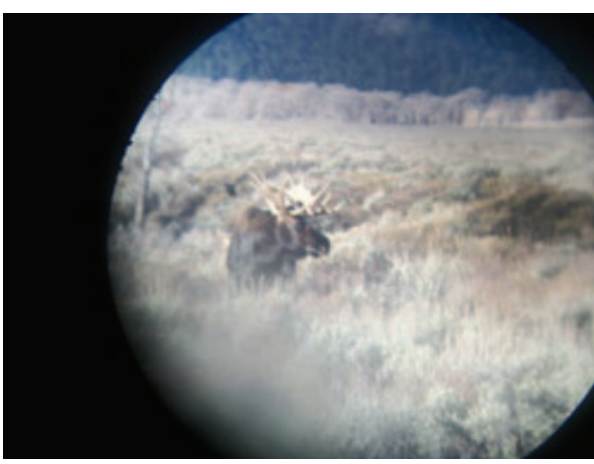

(a) Double-zoomed photo of a wild moose

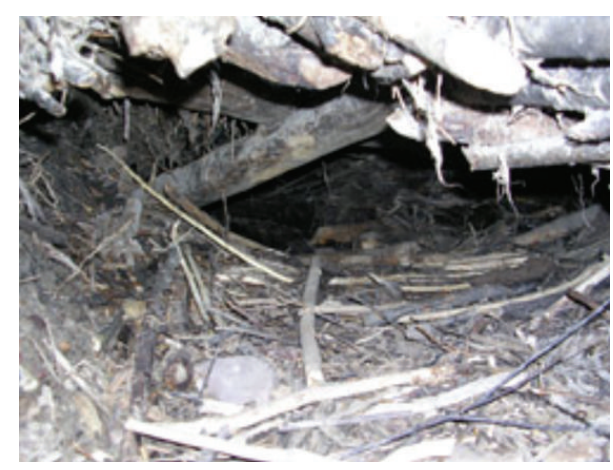

(b) Publicly shared photograph of the interior of a beaver lodge

FIGURE 4: Photographs taken (a) using the magnification capabilities of both binoculars and a camera and (b) to publicly share the interior of an intact beaver lodge.

spaces, and they appeared equally detailed with respect to the information that was being provided. But these were not experiences that students documented as heavily, nor did the students provide the same types of commentary when they reviewed their photographs later. Both types of activities were ones that were emphasized as being unique about this field trip, but students seemed to express a greater tendency to notice and photograph the outdoor activities. They also appeared to have recollections that demonstrated greater sophistication with respect to the depicted science content when the images were associated with outdoor activities.

\section{Documenting Unexpected Students' Uses of Cameras}

Finally, we close with a brief discussion of unexpected uses of the cameras on the field trips. We present in this section two examples that were observed by the author during the field trip. Our goal in presenting these examples is to illustrate that students did not exclusively see the cameras as an instrument for documenting their experiences. Rather, they found new ways to use the cameras throughout the trip that ultimately had impacts on their fellow classmates. Because the students were broken into groups, we could not make an exhaustive list of alternative uses for cameras and thus we just highlight two that were directly observed.

In the first example, we focus on composition. On day 2 , a group of girls were interested in photographing moose that were observable in the distance. These were the first live moose that had been spotted during the trip. For safety reasons, students were not allowed to approach moose or other large wildlife in the field. One girl could see the moose with a pair of binoculars that she had brought with her on the trip, but not with the highest level of zoom on her camera. Knowing that both objects allowed one to see enlargements of objects that cannot be distinguished with the unaided eye and being eager to get a picture of a live moose, she began to experiment with positioning and setting the magnification of her camera with the binoculars so that one was viewed through the other. Other girls near her saw this and began to imitate her, leading to the collection of a few pictures like the one shown in Figure 4(a). This represents a small but thoughtful photography innovation by one student that saw some uptake among the class.

Another noteworthy use of a camera came from a student group that hiked to a river on day 3 for their investigation. They discovered there an intact but abandoned beaver lodge and shifted their investigation to understanding the structure of the beaver lodge. One adventuresome boy decided to crawl inside the lodge and then reach his camera further beyond where he could fit to get photographs that he could share with his group. He was so enthusiastic about the pictures he had taken that he pleaded with his guide to let him show the photographs on an overhead projector during the investigation presentations. When they returned to TSS, and after much searching they found a USB cable and transferred the images so that he could show these to the entire class. This generated so much interest that the teachers made arrangements with the bus driver to take the entire class to the location of the beaver lodge on the return bus ride so that the entire class could see it. After reaching that location, over half of the class then proceeded to climb (through the mud) inside of the beaver lodge so they too could get pictures of the interior. In a sense, the camera served two roles. First, it allowed the boy to get a view of a space that he could not access. Second, the public presentation of the picture of the beaver lodge enabled the entire class to see something unexpected and unique and motivated many of the students to "get their hands dirty" (as well as the rest of their bodies) and get photographs of the inside of the beaver lodge as well. According to the classroom teachers, the intact beaver lodge was a sight never before encountered on any trips to TSS.

These two examples of unexpected uses of the cameras serve to illustrate that, to some extent, students can and will express their own creativity even when using a technology as pervasive and mundane as a digital camera. This is a point raised by Ching et al. [37] in their research as well. These creative uses afford the opportunity for students to obtain and record new perspectives. In one case, we even saw that these new perspectives, if made public, have the potential to completely alter the field trip experience. 


\section{Conclusions}

This study was undertaken with the goal of understanding students' photography behaviors and reflections about science content shown in photographs taken over a multiday field trip to an outdoor science and environmental education site. We observed that students took photographs each day with most photographs taking place during the outdoor activities, specifically those involving guided hike experiences. Such hiking experiences led students toward more inferential comments about what they were encountering than did objects seen in indoor spaces where the artifacts were presented for them in a prepackaged way. Further, while students did take a large number of duplicate images throughout their experiences, by and large students took and were able to thoughtfully articulate ideas associated with unique images and even engage in unexpected photography practices.

What implications might this have for how field trips are led and designed? For one, we believe that student photography during field trips can be a productive activity more than a personal archival one. In Kisiel [9], it was noted that teachers would at times try to be the sole photographer in order to save time. As an alternative, it could be worthwhile to allow students to obtain photographs and share them publicly with their peers as a way to reflect upon and synthesize the experiences and content encountered during their trip. That would serve as another form of posttrip activity design that could enhance the quality of learning from the field trip and its integration with content required within the school. Additionally, teachers might even consider asking students to submit some photographs they had taken following the conclusion of the trip. This could provide a means for teachers to assess what students gained from the field trip with respect to their understandings of science content.

As an aside, through the observations of the trip, we saw a number of activities that had official and explicit designations as being "scientific" by the staff. These included communication exercises, in which students were tasked with providing quantifiable or comparative descriptions similar to what is often reported in scientific research, or measuring by weight the amount of food waste produced at mealtime and seeing if there were any trends over time. While these were promoted by adults as being tied to the science and part of the immersive science experience, these were not obviously registered by students as scientific. Presumably, one of the benefits of place-based learning experiences is that all aspects of the location and the experience are potentially useful material for supporting student learning. This observation of the disconnect between activities that the staff considered scientific but the students did not could inform teachers who repeat these kinds of immersive field trips about where they might want to shift their emphases during field trip preparation activities. For example, the teachers in this study might stress in the future how there are a number of ways in which the tools of science can be used in daily activities and some examples of those will be encountered during the trip. It might be fruitful to also deliberately have a teacher to document these scenes and bring those images back along with ones that students had obtained and initiate discussion about whether or not the photographs showed activities that should legitimately be considered as "scientific."

Ultimately, we are encouraged that there has been some interest in recent years related to the use of photographs in science learning environments and we hope that this work further spurs interest in the research community. Currently, photography is a technology within the easy grasp of children and students are creating unprecedented numbers of visual archives of experience already, be it through their deliberate use of camera on an unusual learning experience or simply through using their mobile smart phones. This is a serious advance over the times when the capture of photographs required great wealth, tremendous expertise, and several minutes to hours of positioning and lighting manipulation to secure a presentable image. Now, we can get an artifact associated with what students see and remember and begin to use those as tools to understand more of what was seen and noticed from the perspective of the students.

Yet it is important to note that this particular study is limited in that it obtained the perspective of students in a fairly narrow way. That is, the experiences were, from the beginning, limited to those that could be and ultimately were photographed. There was already some filtering that students had done by choosing to photograph an event or scene, and that means that despite the high fidelity images, what we glean about the experience is still only an approximation of what had actually happened. Related to this, other aspects of the field trip experience could have left an impression on the students, but this study was not designed to explore those. For example, affective changes from the experience-such as a change in how one feels about the natural environment or particular recurrent tasks-or noteworthy activities that were limited in visual information (as might be the case from a stimulating conversation) were not captured using this version of photo-elicitation methodology. Had those been a major focus of this study, an interview protocol that intentionally elicited such information could have been used. Instead, we simply wanted a record of what students would say in the processes of review and recollection when provided with their own photographs.

Also, this study was modest in size and contained students who all belonged to the same classroom. While some tendencies in photographic behaviors and in the quality of student commentaries about their photographs appeared in this study, it would be inappropriate to make broad generalizations about what kinds of activities definitely encourage particular kinds of behaviors or recall processes or that these behaviors are characteristic of all youth. Moreover, it is possible that there were some ways in which the particular museum-like spaces and the particular individuals involved led to some of the tendencies observed here. For instance, TSS prided itself on its outdoor programming and made that a key feature of the learning experience. It may be that the guides in the program may have exhibited a bias toward providing more engaging experiences when they are leading groups outdoors than when they are leading groups indoors. Based on observations of the guide-student interactions, this was not immediately apparent. However, a comparison in the 
quality of discourse and activity design across the two settings was not part of this work and it would be difficult to reach a firm conclusion without such a study in the future.

While it is clear that further research would be of value, the main goal of this study was to demonstrate that something as familiar and pervasive as students' photographs could be productively tapped as a source of data for educational researchers. So long as privacy concerns are appropriately navigated, images that students capture can be a means for us to understand how intensely interested students were in maintaining a record of a given learning experience. They can also serve as a vehicle for helping researchers to understand how students think about specific scenes and encounters after the experience has ended. This is, admittedly, new territory for educational research and particularly educational research involving outdoor science field trips. Given some recent examples gradually appearing in the literature (e.g., $[43,44])$, we believe this is a territory that will be investigated more thoroughly in the future. We hope to have at least provided here a valid rationale for exploring questions and methods of interest to the environmental and outdoor science education community in the future.

\section{Conflict of Interests}

The author declares that there is no conflict of interests regarding the publication of this paper.

\section{Acknowledgments}

Jeffrey Olsen provided appreciated assistance for this study, and Anne Hunt provided valuable methodological support. Thanks go to the Teton Science School, Josh Kleyman, Anitra Jensen, and Dorothy Dobson, and the participating students.

\section{References}

[1] P. Bell, B. Lewenstein, A. W. Shouse, and M. A. Feder, Learning Science in Informal Environments: People, Places, and Pursuits, National Academies Press, Washington, DC, USA, 2009.

[2] S. K. Davidson, C. Passmore, and D. Anderson, "Learning on zoo field trips: the interaction of the agendas and practices of students, teachers, and zoo educators," Science Education, vol. 94, no. 1, pp. 122-141, 2010.

[3] J. DeWitt and M. Storksdieck, "A short review of school field trips: key findings from the past and implications for the future," Visitor Studies, vol. 11, no. 2, pp. 181-197, 2008.

[4] K. Zoldosova and P. Prokop, "Education in the field influences children's ideas and interest toward science," Journal of Science Education and Technology, vol. 15, no. 3-4, pp. 304-313, 2006.

[5] J. H. Falk and L. D. Dierking, "School field trips: assessing their long-term impact," Curator, vol. 40, no. 3, pp. 211-218, 1997.

[6] J. Farmer, D. Knapp, and G. M. Benton, "An elementary school environmental education field trip: long-term effects on ecological and environmental knowledge and attitude development," Journal of Environmental Education, vol. 38, no. 3, pp. 33-42, 2007.

[7] D. Knapp, "Memorable experiences of a science field trip," School Science and Mathematics, vol. 100, no. 2, pp. 65-72, 2000.
[8] E. Hutchins, Cognition in the Wild, MIT Press, Cambridge, Mass, USA, 1995.

[9] J. Kisiel, "An examination of fieldtrip strategies and their implementation within a natural history museum," Science Education, vol. 90, no. 3, pp. 434-452, 2006.

[10] F. Kato, D. Okabe, M. Ito, and R. Uemoto, "Uses and possibilities of the Keitai camera," in Personal, Portable, Pedestrian: Mobile Phones in Japanese Life, M. Ito, D. Okabe, and M. Matsuda, Eds., pp. 300-310, MIT Press, Cambridge, Mass, USA, 2005.

[11] J. Piaget, The Child's Conception of the World, Harcourt, Brace \& Company, New York, NY, USA, 1929.

[12] J. Bransford, A. L. Brown, and R. R. Cocking, How People Learn: Brain, Mind, Experience, and School, National Academy Press, Washington, DC, USA.

[13] H. Pfundt and R. Duit, Bibliography: Students'Alternative Frameworks and Science Education, Institute for Science Education, Kiel, Germany, 2009.

[14] J. Lobato, B. Rhodehamel, and C. Hohensee, “Noticing' as an alternative transfer of learning process," Journal of the Learning Sciences, vol. 21, no. 3, pp. 433-482, 2012.

[15] M. G. Sherin, V. R. Jacobs, and R. A. Phillipp, Eds., Mathematics Teacher Noticing: Seeing Through Teachers'Eyes, Routledge, New York, NY, USA, 2010.

[16] E. A. van Es and M. G. Sherin, "Mathematics teachers'“learning to notice" in the context of a video club," Teaching and Teacher Education, vol. 24, no. 2, pp. 244-276, 2008.

[17] C. Goodwin, "Professional vision," The American Anthropologist, vol. 96, no. 3, pp. 606-633, 1994.

[18] D. Sobel, Beyond Ecophobia: Reclaiming the Heart in Nature Education, The Orion Society and The Myrin Institute, Great Barrington, Mass, USA, 1996.

[19] G. A. Smith, "Place-based education: learning to be where we are," Phi Delta Kappan, vol. 83, no. 8, pp. 584-594, 2002.

[20] K. Taylor and R. Hall, "Counter-mapping the neighborhood on bicycles: mobilizing youth to reimagine the city," Technology, Knowledge and Learning, vol. 18, no. 1-2, pp. 56-93, 2013.

[21] D. A. Gruenewald, "The best of both worlds: a critical pedagogy of place," Educational Researcher, vol. 32, no. 4, pp. 3-12, 2003.

[22] J. Dewey, Experience and Education, Macmillan, New York, NY, USA, 1959.

[23] N. Orion and A. Hofstein, "Factors that influence leanring during a scientific field trip in a natural environment," Journal of Research in Science Teaching, vol. 31, no. 10, pp. 1097-1119, 1994.

[24] J. H. Falk, W. W. Martin, and J. D. Balling, “The novel field-trip phenomenon: adjustment to novel settings interferes with task learning," Journal of Research in Science Teaching, vol. 15, no. 2, pp. 127-134, 1978.

[25] V. R. Lee, "Adaptations and continuities in the use and design of visual representations in US middle school science textbooks," International Journal of Science Education, vol. 32, no. 8, pp. 1099-1126, 2010.

[26] R. Lemoni, A. G. Stamou, and G. P. Stamou, "Romantic', "Classic" and "Baroque" views of nature: an analysis of pictures about the environment in Greek primary school textbooksdiachronic considerations," Research in Science Education, vol. 41, no. 5, pp. 811-832, 2011.

[27] W. M. Roth and L. Pozzer-Ardenghi, "Pictures in biology education," in Multiple Representations in Biological Education, D. F. Treagust and C. Y. Tsui, Eds., vol. 7, pp. 39-53, Springer, Amsterdam, The Netherlands, 2013. 
[28] J. Umphress, J. Ma, R. Hall, K. H. Taylor, and M. Luna, "Gearing up: new technologies for participant-collected data," in Proceedings of the Annual Meeting of the American Educational Research Association, Vancouver, Canada, April 2012.

[29] M. Clark-Ibáñez, "Framing the social world with photoelicitation interviews," The American Behavioral Scientist, vol. 47, no. 12, pp. 1507-1527, 2004.

[30] D. Harper, "Talking about pictures: a case for photo elicitation," Visual Studies, vol. 17, no. 1, pp. 13-26, 2002.

[31] J. DeWitt and J. Osborne, "Recollections of exhibits: stimulatedrecall interviews with primary school children about science centre visits," International Journal of Science Education, vol. 32, no. 10, pp. 1365-1388, 2010.

[32] S. Tofield, R. K. Coll, B. Vyle, and R. Bolstad, "Zoos as a source of free choice learning," Research in Science \& Technology Education, vol. 21, no. 1, pp. 67-99, 2003.

[33] S. Reeve and P. Bell, "Children's self-documentation and understanding of the concepts "healthy" and 'unhealthy", International Journal of Science Education, vol. 31, no. 14, pp. 1953-1974, 2009.

[34] B. K. Smith, "Bodystorming mobile learning experiences," TechTrends, vol. 58, no. 1, pp. 71-76, 2014.

[35] B. K. Smith, J. Frost, M. Albayrak, and R. Sudhakar, "Facilitating narrative medical discussions of type 1 diabetes with computer visualizations and photography," Patient Education and Counseling, vol. 64, no. 1-3, pp. 313-321, 2006.

[36] M. F. Orellana, "Space and place in an urban landscape: learning from children's views of their social worlds," Visual Studies, vol. 14, no. 1, pp. 73-89, 1999.

[37] C. C. Ching, X. C. Wang, M.-L. Shih, and Y. Kedem, "Digital photography and journals in a kindergarten-first-grade classroom: toward meaningful technology integration in early childhood education," Early Education and Development, vol. 17, no. 3, pp. 347-371, 2006.

[38] D. Tatar and M. Robinson, "Use of the digital camera to increase student interest and learning in high school biology," Journal of Science Education and Technology, vol. 12, no. 2, pp. 89-95, 2003.

[39] R. M. Emerson, R. Fretz, and L. L. Shaw, Writing Ethnographic Fieldnotes, The University of Chicago Press, Chicago, Ill, USA, 1995.

[40] L. W. Anderson and D. R. Krathwohl, A Taxonomy for Learning, Teaching, and Assessing: A Revision of Bloom's Taxonomy of Educational Objectives, Addison Wesley Longman, New York, NY, USA, 2001.

[41] S. J. Kuritz, J. R. Landis, and G. G. Koch, "A general overview of Mantel-Haenszel methods: applications and recent developments," Annual Review of Public Health, vol. 9, pp. 123-160, 1988.

[42] G. W. Somes, "The generalized Mantel-Haenszel statistic," The American Statistician, vol. 40, no. 2, pp. 106-108, 1986.

[43] J. Z. Boxerman, V. R. Lee, and J. Olsen, "As seen through the lens: students' encounters and engagement with science during outdoor field trips," in Proceedings of the Annual Meeting of the American Educational Research Association, San Francisco, Calif, USA, 2013.

[44] E. F. Smith, B. Gidlow, and G. Steel, "Engaging adolescent participants in academic research: the use of photo-elicitation interviews to evaluate school-based outdoor education programmes," Qualitative Research, vol. 12, no. 4, pp. 367-387, 2012. 

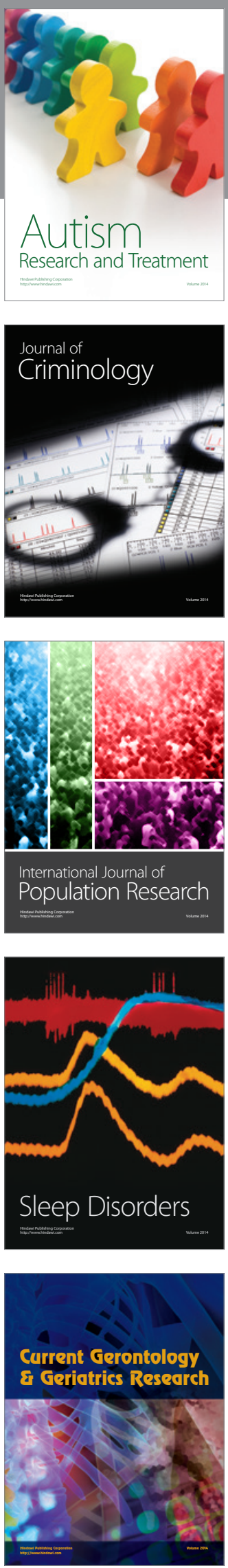
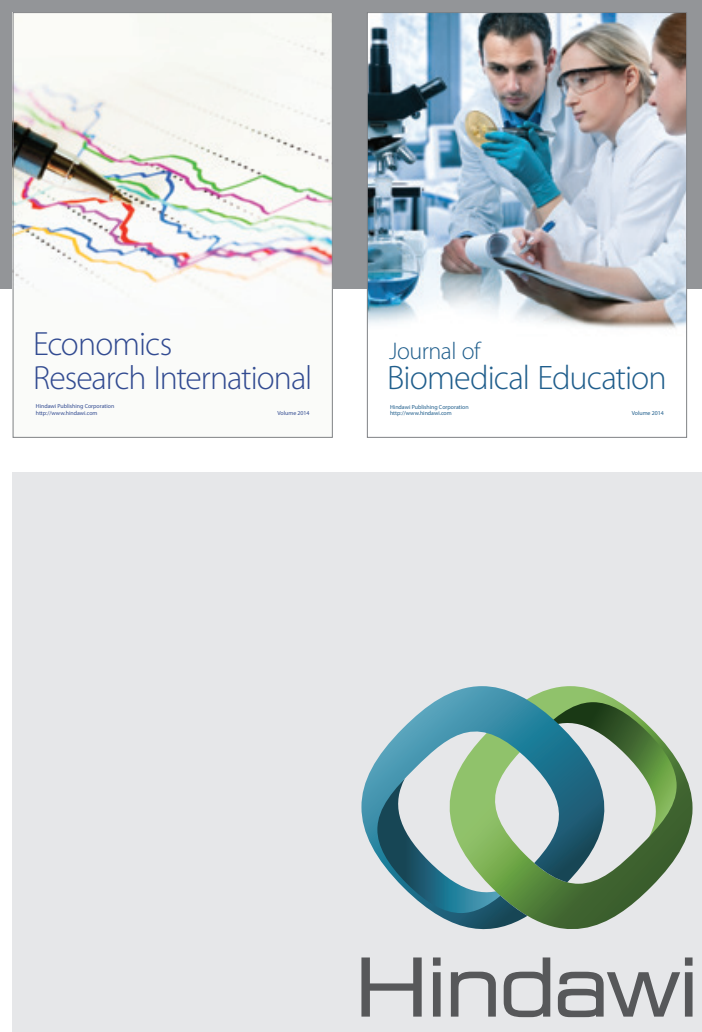

Submit your manuscripts at

http://www.hindawi.com
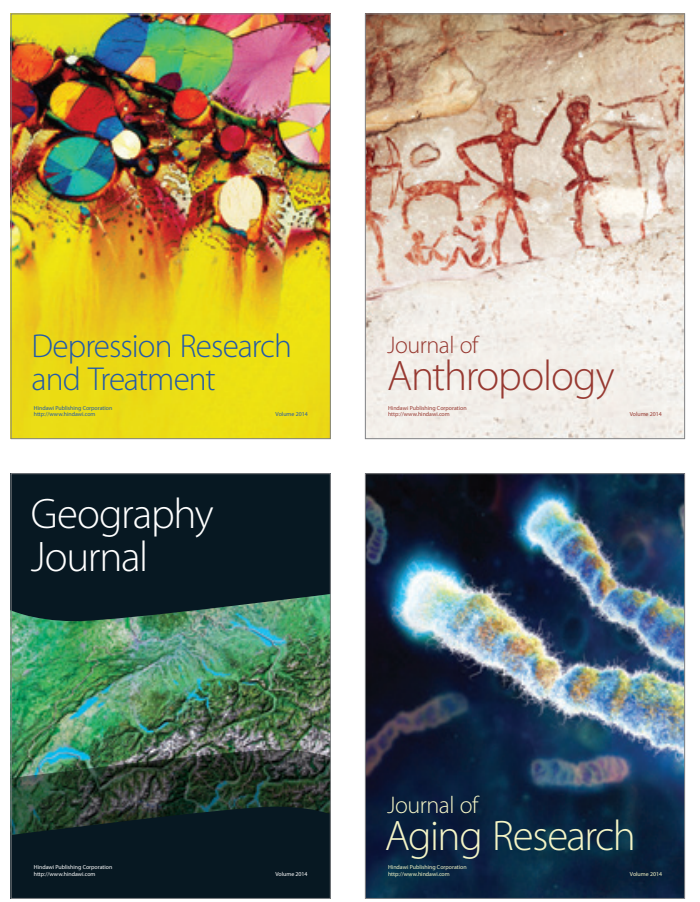
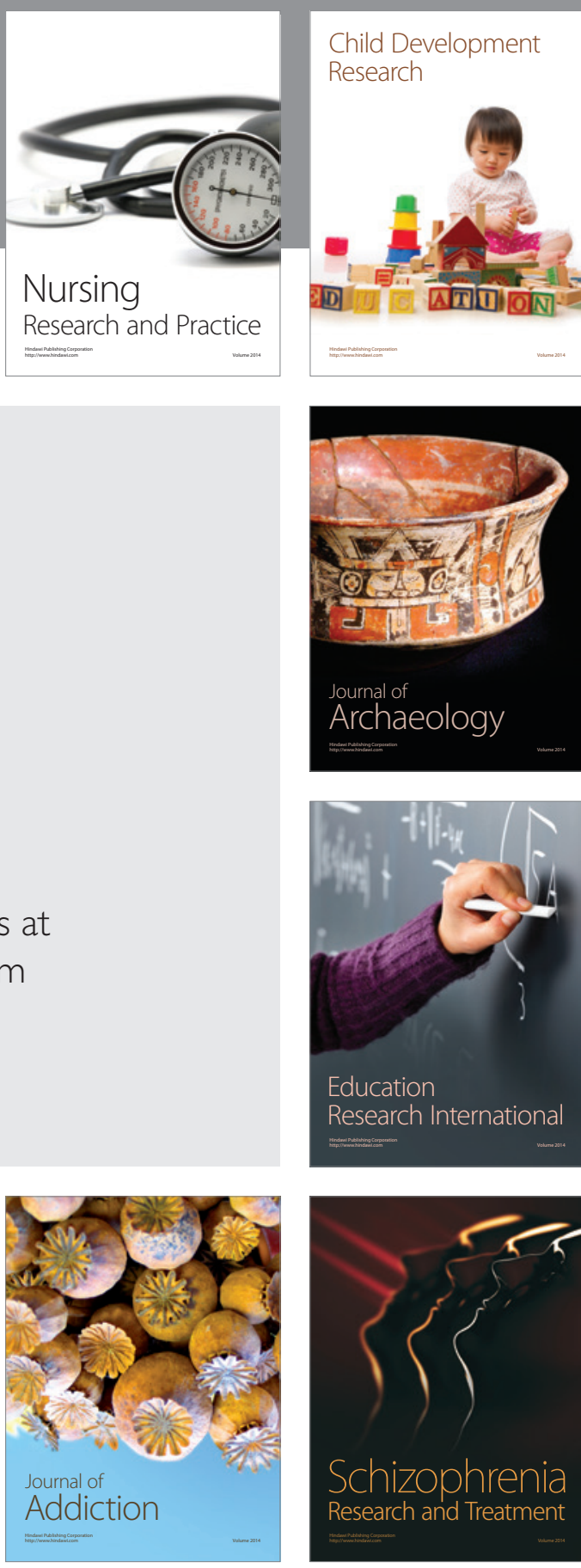

(D)
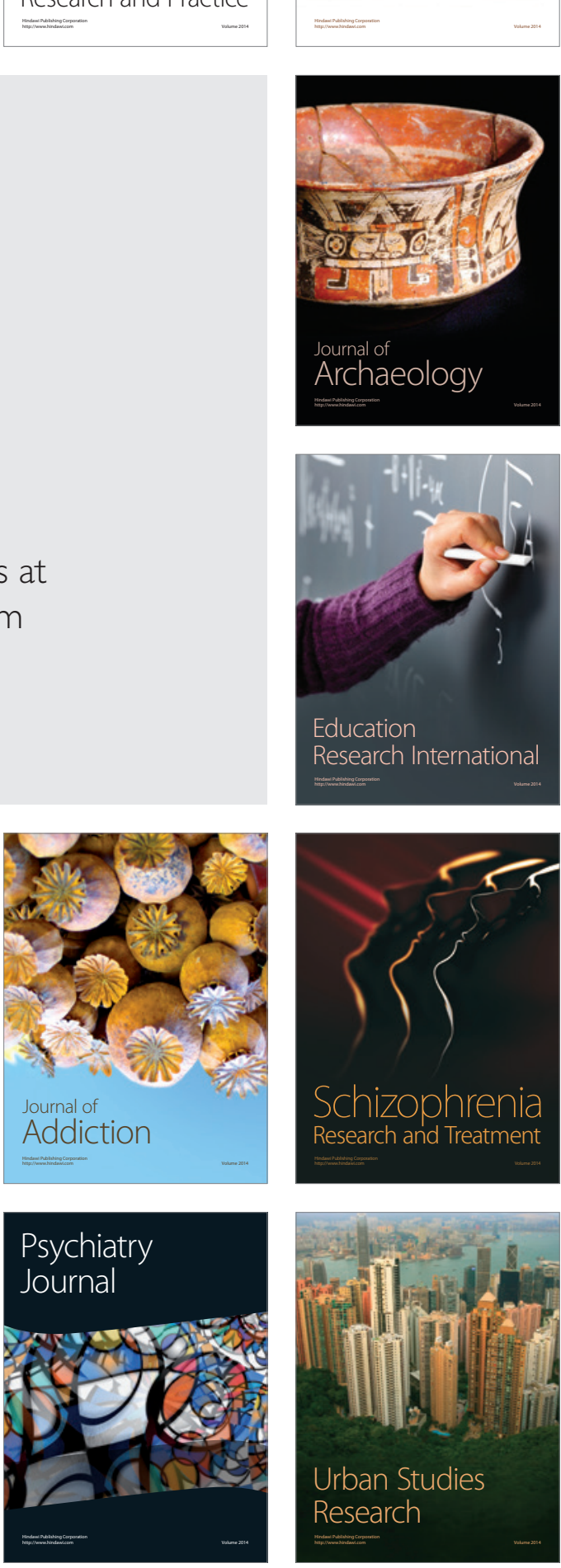